\title{
UNITED STATES
}

Annual Graduate Fortnight of the New York Academy of Medicine.-The New York Academy of Medicine is making arrangements for a series of lectures at the Academy; co-ordinated clinics, clinical demonstrations and courses in hospitals and teaching institutions of New York, on the general subject of "The problem of aging and of old age."

This is to be the first of a number of "Annual Graduate Fortnights', which the Academy is arranging for the benefit of general practitioners and specialists, and will take place the first two weeks of October, beginning October 1, 1928. A number of outstanding authorities will be invited to take part and particular emphasis will be placed upon lectures and courses on the early recognition and prevention of disturbances, commonly ascribed to ageing, but very often not the result of aging but its cause. Courses on functional tests of organs and systems of function, such as circulation, digestion, metabolism, endccrine functions, immunity, etc., are to be offered and the relation of unrecognized forms of intoxication, chemical as well as bacteriological, to the dangers of middle-age are to be specially emphasized.
It is planned to have each year a subject chosen for the Annual Fortnight which is of outstanding importance in the practice of medicine and surgery, and which will be approached from every available angle, with the least loss of time and the greatest possible opportunity to be offered to physicians from out of town.

No fees will be charged, except possibly, where certain special courses are arranged for by medical schools and teaching hospitals, but, in any case, they will be nominal.

The Stanford University Medical School offers a special summer course for graduates of medicine, to be given between Monday, July 2nd and Saturday, July 14, 1928, consisting of a series of forty lectures and demonstrations covering various fields of medicine, surgery, obstetrics, pathology and pharmacology in their clinical aspects.

A detailed programme will be sent on request to anyone interested on application to the Dean, Stanford University Medical School, 2398 Sacramento Street, San Franciseo, California.

\section{JBOok RevíeWs}

Intra-cranial Tumours and Some Errors in Their Diagnosis. Sir James Purves-Stewart, K.C.M.G., C.B., M.D., Senior Physician to the Westminster Hospital, etc., London. Oxford University Press, 1927.

This monograph of some two hundred pages is based upon material collected for the preparation of a presidential address to the Section of Neurology of the Royal Society of Medicine, 1926. One hundred and seventeen verified intra-cranial tumcurs are discussed in such detail as to make an exceedingly valuable contribution to this most interesting subject. To these are added the histories of four cases in which the clinical signs and symptoms simulated those of intra-cranial tumours but were subsequently proved otherwise. The first chapter is devoted in a general way to symptoms and pathology of brain tumours. In dealing specifically with the one hundred and seventeen cases the author groups them anatomically and quotes in extenso the histories of illustrative cases. Valuable criticism of these cases, which cover a period of thirty yesirs, is made. On the whole, the picture of intra-cranial tumours is gloomy: the majority of the patients died but on occasions sur. gical interference was crowned with brilliant results. The lessons to be drawn are that every case must be studied with painstaking exactitude, that localization is essential for successful treatment and that in certain cases brilliant surgical results may be achieved.

FREDERICK BRODIE

Growth of Our Knowledge of Heart Disease. R. O.

Moon, M.A., M.D., F.R.C.P., Consulting Physician to the Royal Waterloo Hospital. 86 pages. Prices \$1.40. Longmans, Green \& Co., Toronto, 1927.

Why does history interest us so deeply 9 . It must be largely for the same reasons that we are interested in growth and change of any kind. There is a difference of course between watching the history of living matter as shown in its development, and following the growth of a science. In the one case we are fascinated by the mystery of the forces which govern the orderly shaping and patterning, but in the other we feel that here is something in which we can take part ourselves, and little as we understand the influences at work even here, we feel more qualified to criticize and suggest alternatives. We may even, in the latter case, enjoy (however much superiority, for it is easy to forget that we are looking
sunconscious of doing so) a certain sense of back at facts which are lighted up for us by torches which we did not kindle.

So that whilst we uncritically watch the growth of living tissues, we are apt to wonder at the slowness with which our knowledge of this growth has developed; and in no respect are we more liable to indulge this critical attitude than in the growth of our knowledge of the heart. We wonder, for example, that it was not until Harvey that the circulation of the blood was completely understood. How was it that Galen could know that the heart expanded and contracted, that it threw blood into the aorta, that the arteries contained blood, and yet could not see the whole cycle of the circulation?

Dr. Moon shows us how difficult it is now to realize what heart disease meant to medical men before the discovery of percussion and ausculation. "Well might Portal, Professor of Anatomy in Paris, say in 1803 that it was to be feared that doctors could not distinguish between different diseases of the heart: it was much if they could recognize at all that the heart was diseased." And yet these diagnostic methods tempted men for some time to direct their attention away from the consideration of the heart muscle itself, though Laennec himself was able to see that here lay the real "key to cardiac pathology." It is doubtful if we have yet learnt to properly discount the meaning of murmurs in the life of the heart. Not-until then will it be possible to make what Dr. Moon indicates as the next great step in our knowledge, namely, the power to estimate the functional efficiency of the heart.

H. E. MACDERMot

Nasal Neurology, Headaches and Eye Disorders. Greenfield Sluder, M.D., F.A.C.S., Clinical Professor and Director of the Department of Oto-Laryngology, Washington University School of Medicine, St. Louis. 428 pages, 167 illustrations. Price $\$ 12.50$. St. Louis: C. V. Mosby Co. Toronto: McAinsh \& Co., 1927.

This is an interesting book of Sluder's personal clinical observations, especially in regard to the cocainization of the nasal ganglion followed by the injection of $1 / 2$ c.c. 5 per cent phenol in 95 per cent alcohol, with the relief of a multitude of symptoms. 